\title{
Cysteine-Cysteinyl Chemokine Receptor 6 Mediates Invariant Natural Killer T Cell Airway Recruitment and Innate Stage Resistance during Mycobacterial Infection
}

\author{
Valerie R. Stolberg ${ }^{a}$ b Bo-chin Chiu ${ }^{a}$ Brian E. Martin ${ }^{a}$ Samir A. Shah ${ }^{b}$ \\ Matyas Sandor $^{c}$ Stephen W. Chensue ${ }^{a, b}$ \\ a Department of Pathology, University of Michigan Medical School Ann Arbor, and bepartment of Pathology \\ and Laboratory Medicine, VA Ann Arbor Healthcare System, Ann Arbor, Mich., and 'Department of Pathology and \\ Laboratory Medicine, University of Wisconsin, Madison, Wisc., USA
}

\section{Key Words}

Chemokine receptors $\cdot$ Cysteine-cysteinyl chemokine receptor $6 \cdot$ Lung $\cdot$ Mycobacteria $\cdot$ Natural killer T cells

\begin{abstract}
This study examined the contribution of cysteine-cysteinyl chemokine receptor 6 (CCR6) to the innate pulmonary antimycobacterial immune response. Using a mouse model of Mycobacterium bovis BCG airway infection, we detected maximal induction of the CCR6 agonist CCL20 in lungs at 1 week after infection. Infected CCR6 knockout (CCR6-/-) mice displayed an early impairment of bacterial clearance, but ultimately eliminated the attenuated organisms with the onset of adaptive immunity. Flow-cytometric analyses of bronchoalveolar lavages and dispersed lungs revealed a $60 \%$ reduction in TCR- $\alpha / \beta+T$ cells in airways but no compromise of TCR- $\gamma / \delta+T$ cells. The subset of CD1d-restricted, CD8-TCR$\alpha / \beta+$ natural killer cells, which mediate innate mycobacterial resistance, was profoundly reduced (90\%). Analysis of the adaptive response using ovalbumin-specific transgenic TCR T cell (OT-II) transfer combined with infection with recombinant $M$. bovis BCG producing ovalbumin peptide indicated no impairment of adaptive T cell activation in CCR6-/- mice. There was also no impairment of the induction of cytokine-
\end{abstract}

producing cells in draining lymphoid tissue of CCR6-/- mice. Taken together, our findings indicate that CCR6 is not required for induction of the adaptive antimycobacterial response, but is likely critical to airway compartment mobilization of TCR- $\alpha / \beta+C C R 6+$ innate and adaptive effector T cells.

Copyright $\odot 2010$ S. Karger AG, Basel

\section{Introduction}

By directing leukocyte migration, chemokine receptors are thought to be essential to mounting an effective antimicrobial response. One such receptor, cysteine-cysteinyl chemokine receptor 6 (CCR6), displays a high degree of genetic homology between mouse and human. Moreover, in both species it is chromosomally segregated from the main chemokine receptor gene cluster [1-3]. Studies using mutant CCR6 knock-in mice revealed that CCR6 is expressed by myeloid dendritic cells (DCs), mature B cells, subpopulations of memory/effector CD4+ and CD8+ T cells, but not plasmacytoid DCs or naïve T cells [4].

CCR6 likely participates in both innate and adaptive phases of immune responses. It was initially purported to be important to DC migration [5-7]. Recently, however,

\section{KARGER}

Fax +4161306 1234

E-Mail karger@karger.ch

www.karger.com (c) 2010 S. Karger AG, Basel

Accessible online at: www.karger.com/jin
Dr. Stephen W. Chensue

Department of Pathology and Laboratory Medicine

113, VAAAHS, 2215 Fuller Road

Ann Arbor, MI 48105 (USA)

Tel. +1 734845 3425, Fax +1 734845 3207, E-Mail schensue@med.umich.edu 
CCR6+ DCs were demonstrated to participate in crosspriming of CD8+ T cells [8] and activation of gut pathogen-specific $\mathrm{T}$ cells [9]. It also reportedly contributes to other T cell-mediated functions such as Th17 migration [10], CD4+ T cell-mediated, delayed-type, hypersensitivity-type, allergic and encephalitic T cell-mediated adaptive responses [11].

In addition to the above, there is evidence that CCR6 may participate in foregut-derived organs such as the lung. For example, airway macrophages and epithelial cells produce its one known chemokine ligand, CCL20 [12-14]. In the human lung the CCR6-CCL20 axis has been implicated to play a role in innate immunity [13], granulomatous conditions such as sarcoidosis [14] and asthma [15]. In view of a potential role in lung immunity, we hypothesized that CCR6 might participate in the response to mycobacteria, an important pulmonary pathogen. To this end, we employed CCR6 knockout mice to test participation of CCR6 in both innate and adaptive stages of the response to Mycobacterium bovis BCG infection. It was important to examine both response stages, since while an adaptive CD4+ Th1 response is required for optimal elimination of mycobacteria, it is well established that innate immune mechanisms participate in the early antimycobacterial response [16]. In particular, natural killer (NK), CD1d-restricted T (invariant NKT, iNKT) and TCR- $\gamma / \delta+$ T cells are reported to retard early mycobacterial expansion [17-20]. Such innate responses are thought to be important in preventing establishment of mycobacteria following low dose exposures.

Our study revealed that despite its purported role in DC function, CCR6 was not required for establishment of T cell-mediated adaptive immunity to M. bovis; however, CCR6 was required for optimal innate stage mycobacterial clearance. Absence of the receptor significantly compromised TCR- $\alpha / \beta+$ T cells and profoundly reduced airway CD1d-restricted iNKT cells which have the innate capacity to recognize mycobacterial glycolipids [21]. In contrast, TCR- $\gamma / \delta+T$ cells were unaffected. Our findings suggest CCR6-mediated airway mobilization of NKT cells is important to innate mycobacterial control.

\section{Materials and Methods}

\section{Animals}

CCR6 knockout mice (CCR6-/-) were generated as described and bred onto a C57BL/6 background [22]. Knockout status was confirmed by RT-PCR analysis. C57BL/6 (CCR6+/+) mice were obtained from Jackson Laboratory (Bar Harbor, Me., USA). CD90.1 (B6.PL-Thyl<a>/CyJ) C57BL/6 congenic and C57BL/6-
$\mathrm{Tg}$ (TcraTcrb) 425Cbn/J TCR transgenic (OT-II) mice were purchased from Jackson Laboratory. CD4+ T cells from the OT-II mice are specific for ovalbumin (OVA) peptide 323-339 (EKLTEWTSSNVMEER) in the context of I-Ab (26). OT-II TCR transgenic mice expressing CD 90.1 on C57BL/6 background were bred using male OT-II and female B6.PL-Thyla/CyJ mice. Mice were maintained under specific pathogen-free conditions and provided with food and water ad libitum in a UCUCA-approved facility. All studies were approved by an institutional review board.

\section{M. bovis BCG Strains and Colony-Forming Unit}

Determinations

M. bovis BCG, Pasteur strain (Trudeau Institute, Saranac Lake, N.Y., USA) was propagated in liquid 7H9 medium supplemented with $0.5 \%$ glycerol, $10 \%$ oleic acid-albumin-dextrose-catalase (OADC) and $0.05 \%$ Tween 80 . Organisms were harvested in mid-log growth phase, usually $16-20$ days of culture at $37^{\circ} \mathrm{C}$ in a humidified $6 \% \mathrm{CO}_{2}$ atmosphere. BCG was stored at $-80^{\circ} \mathrm{C}$ in PBS-glycerol (1:1). Preparations were washed with PBS before in vivo administration.

Recombinant BCG-OVA was prepared using a construct containing the green fluorescent protein (GFP) gene driven by a mycobacterial Hsp60 promoter and carrying a kanamycin resistance gene, which was provided by Glenn Fennelly (Albert Einstein Yeshiva University, New York, N.Y., USA). OVA peptides recognized by the OT-I and OT-II TCR transgenic T cells were cloned by PCR into the C-terminal end of the GFP molecule using extended primers. The altered construct was checked by sequencing, then BCG Pasteur was transfected with the OVA peptide construct and selected in kanamycin-containing media. The transfected BCG were GFP positive and in in vitro splenic cultures both OT-I and OT-II cells were activated by the recombinant bacteria or bacterial lysates. Production of peptides was also confirmed by Western blotting. The course of BCG infection and the bacterial load determined by colony-forming units (CFU) were very similar in C57B6 mice infected with the wild-type or the recombinant GFPOVA-BCG.

CFU were determined from serially diluted preparations distributed on Middlebrook 7H10 agar $(100 \mathrm{~mm})$ plates with OADC supplement. For lung CFU, whole lungs were homogenized in 20 $\mathrm{ml}$ of sterile PBS using a Waring blender. Plates were cultured at $37^{\circ} \mathrm{C}$ in a humidified $6 \% \mathrm{CO}_{2}$ atmosphere for $2-3$ weeks.

\section{M. bovis Infection}

One million $M$. bovis BCG CFU were administered by intratracheal route. Briefly, mice were subjected to ketamine/xylazine anesthesia and then secured by soft restraint to an operating board to expose the neck. After iodine field disinfection, a 5 to $6 \mathrm{~mm}$ midline incision was made to expose the trachea. Using a $26 \mathrm{G}$ needle and syringe, mycobacteria suspended in a $20-\mu \mathrm{l}$ PBS were injected in the tracheal lumen followed by closure of the skin wound with 4-0 Softsilk sutures on a C-13 cutting needle. For recovery, mice were placed on a water-jacketed heating pad to maintain body temperature.

\section{Cell Preparation and Flow Cytometry}

Prior to lung excision, bronchoalveolar lavage (BAL) was performed by inserting $0.58-\mathrm{mm}$ diameter polyethylene tubing (BD Biosciences, San Jose, Calif., USA) into the trachea and secured with 4-0 Softsilk suture material. Using a 3-way stopcock, $2 \mathrm{ml}$ 
volumes of cold RPMI 1640 (Sigma Aldrich, St. Louis, Mo., USA) were pushed by syringe into the lungs and subsequently withdrawn into a second syringe. Lungs were washed with a total of 10 $\mathrm{ml}$ of RPMI. BAL fluid was then placed in a $50-\mathrm{ml}$ collection tube. After lavage, cell suspensions were prepared from enzymatically dispersed lungs as described [23]. Total cell yields were determined by standard hemocytometric counting.

Antibodies used included FITC-, PE-, PE-Cy5-, Pacific Blueand APC-conjugated anti-CCR6 (CD196, 29-2L17), CD4 (GK1.5), anti-CD8a (53-6.7), anti-TCR- $\alpha / \beta$ (H57-597), anti-TCR- $\gamma / \delta$ (UC7-13D5), anti-CD44 (IM7), anti-NK1.1 (PK136), anti-CD90.1 (HIS51) and anti-CD90.2 (53-2.1) (from BD Biosciences, eBioscience, San Diego, Calif., USA, or Biolegend, San Diego, Calif., USA). Isotype controls and anti-CD16/CD32 (2.4G2) were from eBioscience. After blocking with anti-CD16/CD32 for $5 \mathrm{~min}$, cells were stained with fluorescence-labeled antibodies or isotype control antibodies in 2\% FBS-PBS staining buffer for 25 min at $4^{\circ} \mathrm{C}$. iNKT cells were identified using FITC-labeled tetramer (obtained from the NIH Tetramer Core Facility, Atlanta, Ga., USA) and further confirmed using commercially available PE-labeled CD1d tetramer (loaded and unloaded; ProImmune, Bradenton, Fla., USA). Briefly, $100 \mu \mathrm{l}$ of staining buffer and $0.5 \mu$ l of either loaded or unloaded (control) tetramer was added to each anti-CD16/CD32 blocked sample then incubated for $30 \mathrm{~min}$ at $4^{\circ} \mathrm{C}$. After washing, a second staining for additional surface markers was performed. NKT cells were defined as CD1tetramer+ TCR- $\alpha / \beta+$ CD 8 - cells. A FACScan LSRII multicolor flow cytometer (BD Biosciences) with FlowJo software (Tree Star, Ashland, Oreg., USA) was used for data acquisition and analysis.

For cytokine determination, draining mediastinal lymph nodes were teased and then suspended in RPMI-supplemented medium (RPMI with 20 mM HEPES buffer, 10\% fetal bovine serum, $100 \mathrm{U}$ penicillin and $100 \mu \mathrm{g} / \mathrm{ml}$ streptomycin) at $5 \times 106$ cells $/ \mathrm{ml}$. The cells were cultured in the presence or absence of $10 \mu \mathrm{g} / \mathrm{ml} \mathrm{M}$. bovis purified protein derivative and incubated at $37^{\circ} \mathrm{C}$ with $5 \% \mathrm{CO}_{2}$ for $48 \mathrm{~h}$. Cell-free supernates were collected by centrifugation, then IFN- $\gamma$ and IL-17A levels were measured by commercially available ELISA reagents (R\&D Systems, Minneapolis, Minn., USA).

\section{In vivo Transgenic $T$ Cell Proliferation}

In vivo antigen presentation was detected using adoptive transfer of carboxyfluorescein succinimidyl ester (CFSE; Invitrogen, Carlsbad, Calif., USA) labeled CD4+ T cells from transgenic mice with OVA peptide-specific TCR (OT-II) as described [24]. CCR6+/+ and CCR6-/- mice were exposed to 1 million recombinant $M$. bovis BCG-OVA intratracheally and on day 8 received 5 million CFSE-labeled, CD4+, CD90.1+ OT-II transgenic T cells. On day 14 , draining lymph nodes and spleens were subjected to flow-cytometric analysis.

\section{RNA Purification and Real-Time RT-PCR Analysis}

RNA was isolated, reverse transcribed and used for real-time PCR analyses as previously described [25]. Analysis of CCL20 transcripts was performed by real-time PCR using the ABI PRISM 7000 Sequence Detection System (Applied Biosystems, Foster City, Calif., USA) as previously described [26]. RNA sequencespecific primer probe sets for mouse CCL20 and the housekeeping gene GAPDH were obtained commercially (Applied Biosys- tems). The comparative threshold cycle method recommended by the manufacturer was adopted. GAPDH was used as the endogenous reference. The thermal cycling condition was programmed according to the manufacturer's instructions. Transcript levels were expressed as arbitrary units and were calculated as previously described [27].

\section{CCL20 Immunoassay}

Mouse CCL20 was measured in aqueous lung extracts and BAL by ELISA using a commercially available kit (R\&D Systems). Assay sensitivity was to $2-4 \mathrm{pg} / \mathrm{ml}$. Aqueous extracts of lungs were prepared as previously described [26]. Levels of CCL20 were normalized to total extracted protein and expressed as picogram of chemokine per milligram lung protein.

\section{Statistical Analysis}

Student's t test was used for direct comparison to a parallel control group and one-way analysis of variance (ANOVA) for multigroup analyses. Values of $\mathrm{p}<0.05$ were considered to indicate significance.

\section{Results}

\section{CCL20 Transcripts Are Induced in Lungs following}

$\mathrm{M}$. bovis BCG Infection

In contrast to virulent $M$. tuberculosis, which is uniformly fatal in most mouse strains, $M$. bovis BCG is an attenuated vaccine strain which is ultimately controlled even by highly immunocompromised mice. Thus, BCG provides a means to examine innate and adaptive antimycobacterial immune responses in mice. In addition, to eliciting multiple innate immune mechanisms in the early stages of pulmonary infection, BCG is known to elicit a highly polarized IFN- $\gamma$-dominant adaptive response involving both CD4+ and CD8+ T cells. To determine the potential involvement of CCR6, we first assessed the temporal transcript expression of its one known chemokine agonist, CCL20, formerly known as liver- and activationregulated chemokine (LARC), in lungs after intratracheal BCG exposure of C57BL/6 mice. As shown in figure 1, CCL20 transcripts were induced and reached a maximum by 1 week following infection. Transcript levels correlated well with protein expression in lungs (fig. 1, inset). Thereafter, expression declined reaching baseline by 6 weeks. Thus, CCR6 agonist expression appeared prior to the onset of the adaptive response which is manifest after 2 weeks [28].

\section{CCR6 Knockout Mice Display an Early Bacterial} Clearance Defect following M. bovis BCG Infection

As it appeared that BCG infection elicited CCR6 agonist expression in lungs, we next tested the effect of 


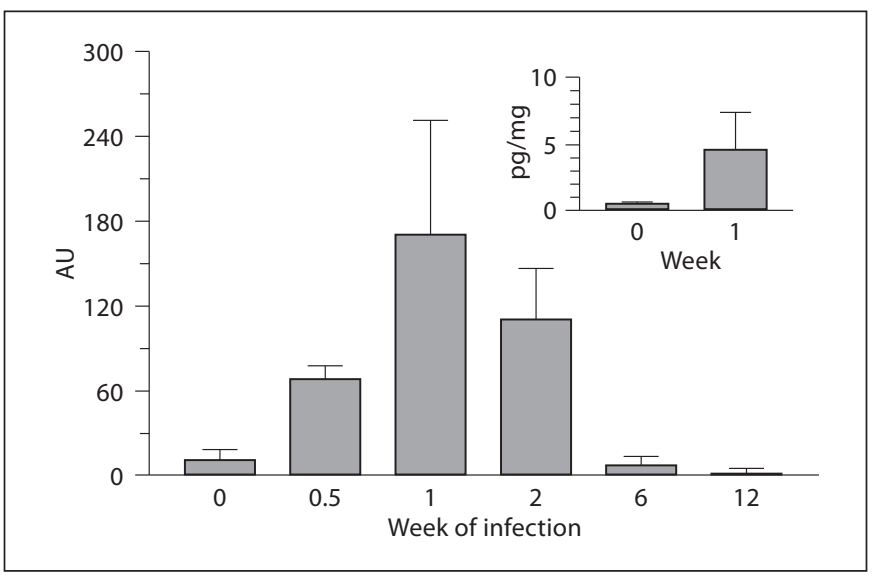

Fig. 1. Induction of CCL20 transcripts in lungs following $M$. bovis BCG intratracheal infection. Naïve C57BL/6 mice were exposed to 1 million $M$. bovis BCG organisms intratracheally, and then lungs were excised at designated intervals for measurement of CCL20 transcripts by real-time RT-PCR. Bars are means \pm SD of 5-6 individual mice. Inset shows corresponding protein levels of CCL20 in naïve and 1-week-infected mice as measured in lung extracts and normalized to the level of extracted protein $(\mathrm{pg} / \mathrm{mg})$. Time 0 represents naïve pre-exposure mice.

CCR6 knockout on the course of infection. Groups of control (CCR6+/+) and knockout (CCR6-/-) mice were infected intratracheally and then mycobacterial CFU were measured in lungs at designated intervals. Figure 2 shows that the day after infection control and knockout mice had equivalent levels of organisms in lungs. Thereafter, CCR6-/- displayed impaired early stage mycobacterial clearance with levels persisting over 2 weeks. However, by 8-12 weeks CCR6-/- mice had largely eliminated organisms similar to controls. Since the adaptive response to mycobacteria does not manifest in lungs until after 2 weeks [28], this finding suggested that early innate resistance was impaired in CCR6-/- mice in the period prior to this time. However, impaired induction of adaptive immune cells could not be completely ruled out.

\section{M. bovis BCG-Infected CCR6 Knockout Mice Display}

Reduced Airway Recruitment of TCR- $\alpha / \beta$ T Cells

with Profound Impairment of iNKT Cell Mobilization

To explore possible mechanisms for the impaired early control of mycobacteria in CCR6 mice we prepared BAL and dispersed lung cell suspensions from BCG-infected mice on days 4 and 8 after infection and performed flow cytometry to identify and quantify important $\mathrm{T}$ cell subpopulations in the airway and interstitial compart-

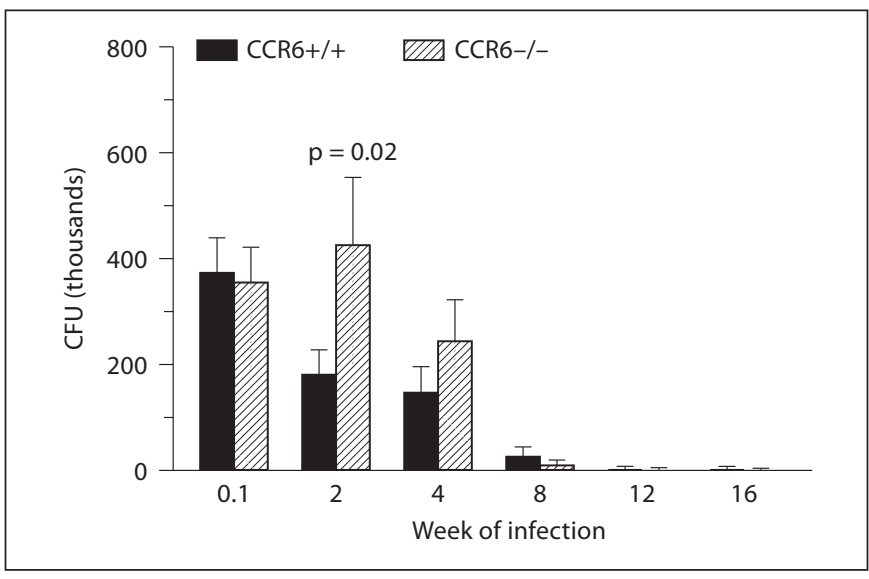

Fig. 2. Comparison of $M$. bovis BCG clearance in lungs of control and CCR6 knockout mice. Groups of naïve control (CCR6+/+) and CCR6 knockout (CCR6-/-) C57BL/6 mice were infected as described in the Materials and Methods section. At designated intervals, mice were sacrificed and mycobacterial CFU determined in homogenized lungs. To determine equivalency of initially established infection, groups of mice were sampled $16 \mathrm{~h}$ (0.1 week) after infection. Bars show means \pm SE of 5 individual mice.

ments. As shown in figure 3, T cells overall appeared to increase in airways over the 8-day study period. However, CCR6-/- mice displayed $60 \%$ reductions in TCR- $\alpha / \beta+$ T cells, whereas TCR- $\gamma / \delta+\mathrm{T}$ cells were unaffected. Using PBS57-loaded tetramer to identify the subpopulation of CD1d-restricted TCR- $\alpha / \beta+$ cells known as iNKT cells, it was determined that this population was profoundly decreased with an over $90 \%$ reduction observed by day 8 . This population is of particular significance, since they reportedly provide innate resistance to mycobacteria by their ability to recognize mycobacterial glycolipids [29, 30]. When this population was measured in the lung parenchyma no differences were observed between control and knockout mice (fig. 3). This suggested that CCR6 was required for airway migration, but not parenchymal compartment localization of TCR- $\alpha / \beta+$ T cells.

Lung Parenchymal TCR- $\alpha / \beta+$ T Cells and iNKT Cells Express CCR6 in M. bovis BCG-Infected Mice

In order to determine the relationship of the TCR- $\alpha / \beta$ $T$ cell recruitment defect and CCR6 we assessed the expression CCR6 among lung T cells at day 7 of BCG infection by flow-cytometric analysis. CCR6 is known to be expressed by a number of leukocyte populations including T memory/effector cells. In addition, CCR6 has recently been described among iNKT cells in humans [31] 
Fig. 3. Effect of CCR6 knockout on innate stage $T$ cell populations in airway and lung interstitial compartments of $M$. bovis BCGinfected mice. Naïve control $(\mathrm{CCR} 6+/+)$ and CCR6 knockout (CCR6-/-) C57BL/6 mice were infected with BCG as described in the Materials and Methods section, and then BAL and dispersed lung preparations were subjected to multicolor flow cytometric analysis to detect TCR- $\alpha / \beta$, iNKT and TCR- $\gamma / \delta$ T cell populations on days 4 and 8 , prior to the onset of adaptive antimycobacterial immunity. Bars show means \pm SEM of 3 separate experiments with 4-6 mice in each group per experiment. ${ }^{*} \mathrm{p}<0.05$ compared to matched controls.



and mice [32]. However, CCR6 expression has not been examined among iNKT cells during mycobacterial infection.

When assessing chemokine receptor expression it is critical to be aware of their dynamic nature as related to tissue compartment migration. Different chemokine receptors are thought to allow cell movement into different tissue subcompartments, with regulation of receptor expression upon ligand encounter. For example, in humans, CCR6 is downregulated on T cells upon ligand encounter and migration into lung airways [33]. As this might also occur in mice, we compared CCR6 expression in lung airway and parenchymal compartments by respective examination of cells in BAL and postlavage collagenase-dis- 


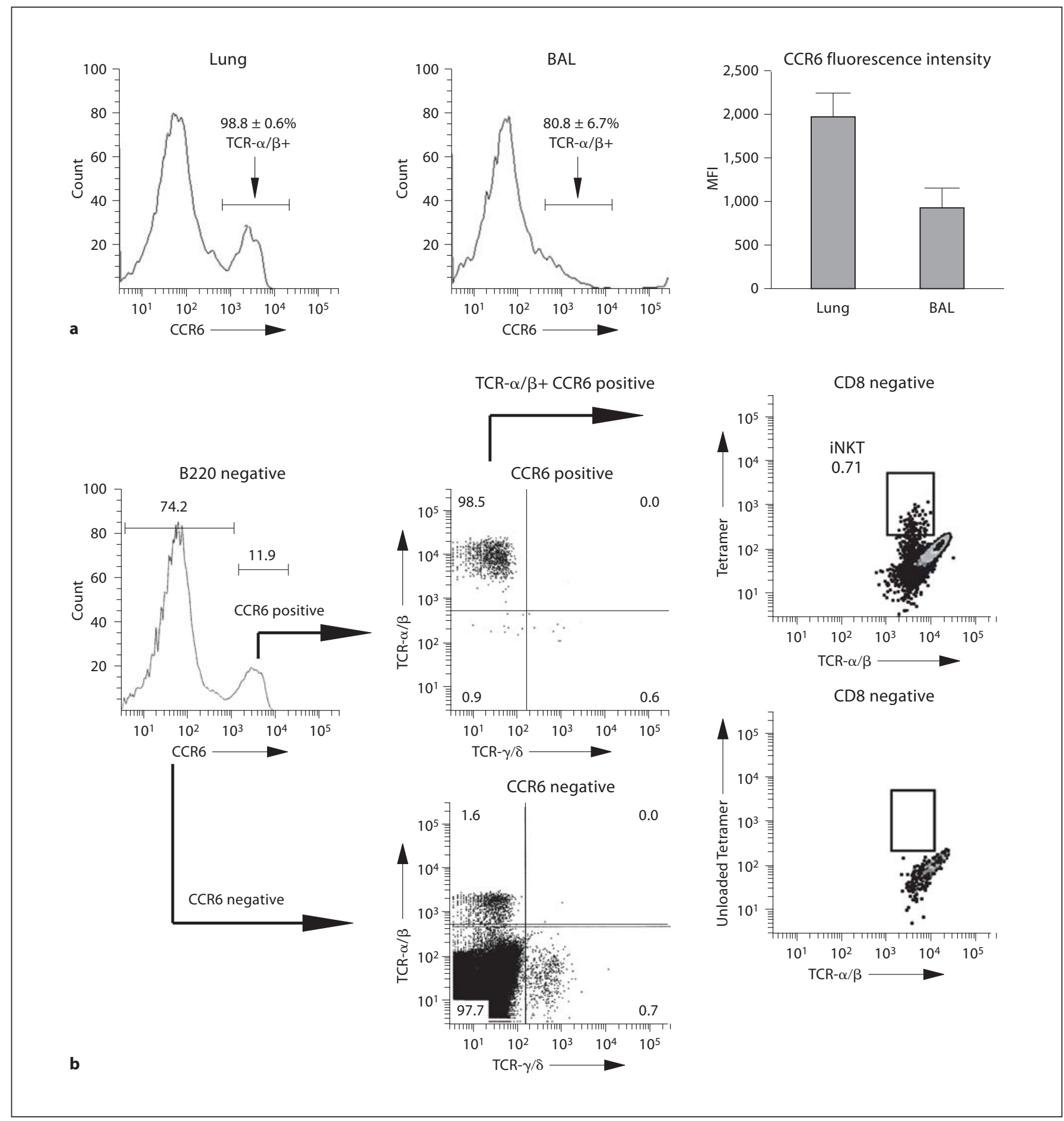

Fig. 4. Expression of CCR6 by lung and airway T cell populations. Naïve C57BL/6 mice were infected with BCG as described in the Materials and Methods section, and on day 7 mice were sacrificed to prepare BAL and lung digests for multicolor flow cytometric analysis. a Representative histograms of CCR6 expression among matched lung digest and BAL cells are shown, the means of fluorescence indices (MFI) were derived from 5 separate mice. In lungs, CCR6+ cells were nearly all TCR- $\alpha / \beta+\mathrm{T}$ cells $(98.8 \%)$.
CCR6 expression was downregulated among BAL compared to lung parenchymal TCR- $\alpha / \beta+$ cells. b Representative histogram and scattergram analyses of CCR6-positive and CCR6-negative populations in dispersed lungs. CCR6 is expressed principally by a subpopulation of TCR- $\alpha / \beta+$ T cells which includes CD8-negative iNKT cells. A parallel stained preparation with unloaded tetramer control is shown. 
persed lung preparations. Figure 4a shows an analysis 7 days after M. bovis BCG infection when CCR6 ligand expression is maximal. Notably, a CCR6+ bright population was identified in lung parenchyma which was composed predominantly $(98.8 \pm 0.6 \%)$ of TCR- $\alpha / \beta+$ cells. In airways, the CCR6+ population was lost or became weakly positive. Analysis of mean fluorescence intensity also indicated reduced CCR6 expression among the latter (fig. 4a). This airway CCR6 dim population was composed predominantly $(80.8 \pm 6.7 \%)$ of TCR- $\alpha / \beta+$ cells. These were likewise CD44+ consistent with being effector/memory $\mathrm{T}$ cells (data not shown). Since knockout studies indicated CCR6 was required for optimal airway TCR- $\alpha / \beta+$ cell recruitment, this finding suggested the receptor was downregulated among $\mathrm{T}$ cells as they encounter ligand during airway migration, agreeing with that reported for human airway T cells by Thomas et al. [33].

A detailed analysis of the CCR6+ lung parenchyma cells indicated, as noted above, that they were almost exclusively TCR $-\alpha / \beta+$ T cells. In contrast, the CCR6 negative population included TCR- $\alpha / \beta+$ and TCR $-\gamma / \delta+\mathrm{T}$ cells as well as non-T cells (fig. 4b). The TCR- $\alpha / \beta+$ population in the lung was $60 \pm 1.7 \% \mathrm{CD} 4+$ and $37.5 \pm 1.7 \%$ CD8+. The CCR6+ TCR- $\alpha / \beta+$ CD8- population included a small subpopulation $(1.5 \pm 1.4 \%, \mathrm{n}=5)$ of CD1dligand tetramer binding cells consistent with iNKT cells (fig. 4b). Taken together, these studies indicated that BCG-infected lungs harbored a population of CCR6+ TCR- $\alpha / \beta+$ T cells which included CCR6+ iNKT cells.

CCR6 Knockout Mice Display Normal Induction of Adaptive T Cell Responses following M. bovis BCG Infection

Since CCR6 is purported to play a role in DC migration it was important to determine if it contributed to the early mycobacterial clearance defect due to impaired induction of the adaptive response. To this end, we examined possible effects of CCR6 knockout on antigen presentation and cytokine-producing capacity in pulmonary draining lymph nodes. It has been previously demonstrated that unlike with soluble antigen the adaptive response to airway mycobacterial infection is delayed and not generated until 10-14 days after exposure [28]. Therefore, in order to assess infection-related Ag presentation in vivo, we utilized OVA-specific transgenic CD4+T cell (OT-II) transfer on day 7 after infection of CCR6-/- and control mice with a recombinant BCG strain synthesizing OVA peptide (rBCG-OVA). Subsequently, T cell proliferation was measured on day 14 in draining lymph nodes and spleens. As shown in figure $5 \mathrm{a}$, knockout mice displayed a similar degree of proliferation as controls with at least 4 daughter generations detected. Moreover, analysis of spleens showed that proliferation was limited to the lymph node, indicating the draining node was the main site of Ag presentation and effector cells had not yet substantially populated the periphery. Hence, the CCR6 knockout environment could support Ag-presentation and T cell proliferation with similar kinetics as control mice.

We also assessed the capacity of lymph nodes to produce IFN- $\gamma$ and IL-17 over the course of infection. These cytokines are thought to contribute to adaptive immune resistance to mycobacteria. As shown in figure 5b, these cytokines were most dominant at the 2 week time point with subsequent decline consistent with the local generation of effector cells followed by redistribution to the periphery. Over the study period, CCR6-/- mice showed no significant differences from controls. Taken together with the $\mathrm{T}$ cell proliferation study, these findings indicated that CCR6-/- mice generated an adequate adaptive antimycobacterial response.

\section{Discussion}

M. tuberculosis infection is well recognized as a worldwide health threat affecting about a third of the human population with an infection-related death occurring every $10 \mathrm{~s}$. Mycobacteria are known to be ingested by airway macrophages and are then carried into the lung interstitium where they further multiply if not eliminated. A spectrum of immune responses is mounted against this organism; however, it has evolved a variety of evasive countermeasures to avoid elimination. Among the latter, the organism has the capacity to delay the development of adaptive immunity. In spite of this, the exposure rate to $M$. tuberculosis exceeds the rate of sustained infection such that only $20 \%$ of exposures cause disease [34]. This observation is likely related to effective innate airway resistance which limits or prevents infection early after exposure. Therefore, understanding and augmenting innate resistance represents an important aim in efforts to prevent infection.

While the production of CCR6 ligand, CCL20, has been recognized in $M$. tuberculosis patients [35], there is little knowledge regarding its role in the disease. The present study examined the contribution of the chemokine receptor, CCR6, to innate and adaptive responses to mycobacterial infection using a murine model of $M$. bovis BCG infection. Ligand expression for this receptor preceded the induction of the adaptive response achieving a 
Fig. 5. CCR6 knockout does not impair adaptive stage induction of the naïve $\mathrm{T}$ cell proliferative response or cytokine production in draining lymph nodes. a In vivo proliferation of adoptively transferred CFSE-labeled OVA peptide-specific transgenic CD4+CD90.1+ T cells (OTII) in mice infected with recombinant $M$. bovis BCG (rBCG-OVA) producing OVA peptide (see Materials and Methods). Transgenic cells were transferred to control and knockout mice on day 8 of infection. Draining mediastinal lymph nodes and spleens were then analyzed by flow cytometry on day 14 . Representative scattergrams are shown. The findings were repeated in 3 experiments. b Levels of cytokines produced by cultured draining mediastinal lymph nodes obtained from control $(\mathrm{CCR} 6+/+)$ and knockout (CCR6-/-) mice at designated intervals after infection with standard $M$. bovis BCG. Bars show means \pm SD of 5-6 individual mice.

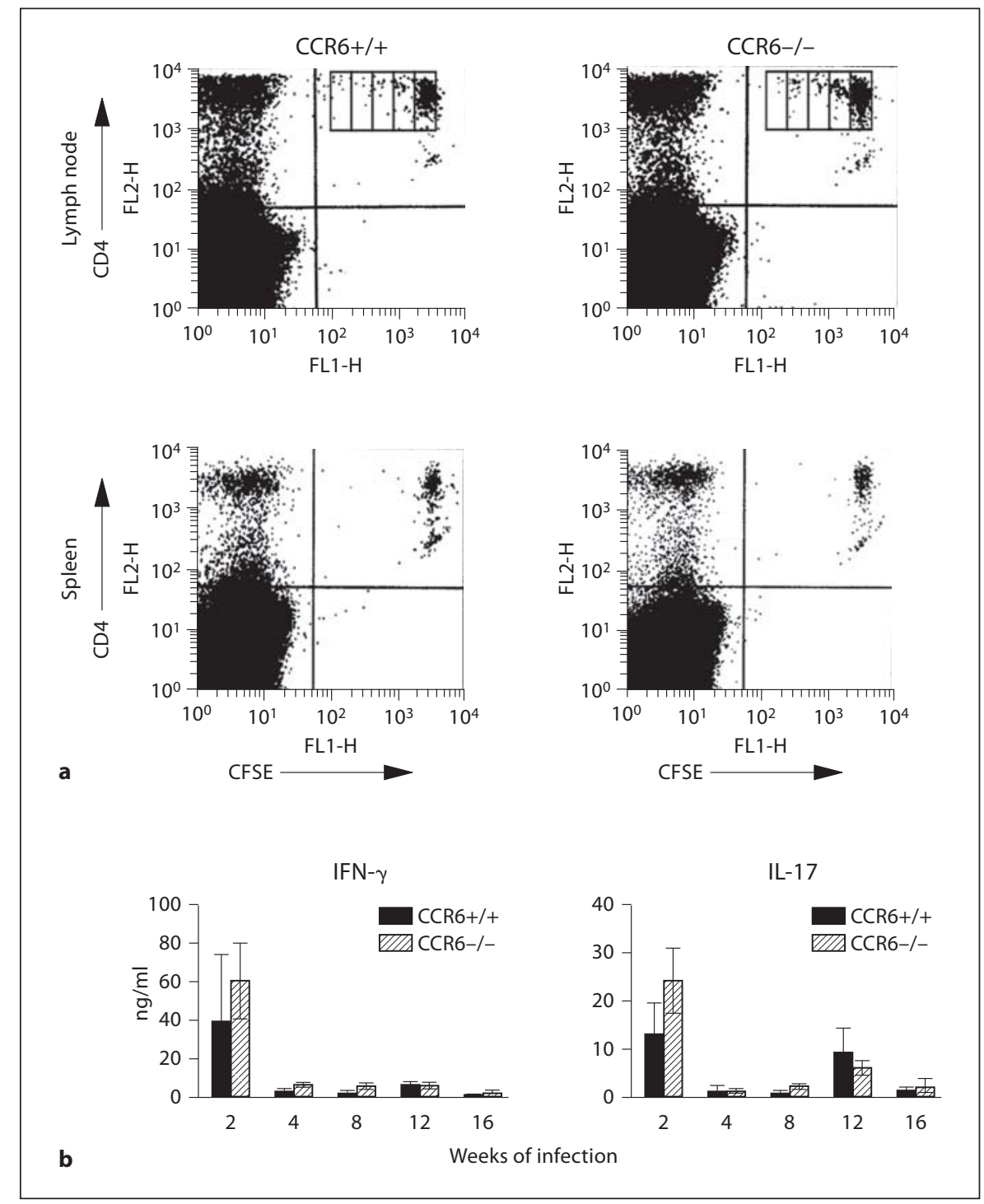

maximum in lungs by 1 week after primary infection and thereafter declining. The pattern of induction suggested that the ligand was induced after airway exposure during the early pre-adaptive stage of infection and would be consistent with known production of this chemokine by airway epithelial cells [13].

Using CCR6 knockout mice we established that this receptor was required for bacterial clearance in the preadaptive phase ( $0-2$ weeks) and was needed for optimal airway recruitment of TCR- $\alpha / \beta$ T cells which included a small subset of innate responsive NKT cells. The latter defect was likely responsible for the impaired innate stage clearance, as CD1-restricted or iNKT cells are known to promote mycobacterial resistance $[36,37]$. They repre- sent a specialized TCR- $\alpha / \beta$ T cell subpopulation with the capacity for innate recognition of mycobacterial glycolipids [37]. While representing a small component of the TCR- $\alpha / \beta$ T cell pool, iNKT cells behave like innate responders through their ability to directly recognize mycobacterial glycolipids. Hence, unlike conventional TCR$\alpha / \beta$ T cells which are TCR-MHC restricted, iNKT cells can respond broadly and rapidly to mycobacteria. It is noteworthy that humans with low circulating levels of NKT cells are more susceptible to tuberculosis infection [38]. Our findings point to CCR6 as a key mechanistic element of NKT cell-mediated resistance likely by providing cells access to the airway and potential contact with macrophages containing ingested bacteria [30]. 
Interestingly, CCR6 knockout mice showed no defect in airway recruitment of TCR- $\gamma / \delta \mathrm{T}$ cells which represent a specialized $\mathrm{T}$ cell population considered to be innate responders. These cells have long been known to be elicited following $M$. bovis BCG infection and have been implicated in conferring resistance, possibly at the level of granuloma formation [39, 40]. However, our results suggest that these cells contribute minimally to innate mycobacterial resistance at the airway level and reaffirm the critical role of TCR- $\alpha / \beta$ T cells. Furthermore, analysis of CCR6 expression indicated that most TCR- $\gamma / \delta$ T cells in BCG-infected mice did not express CCR6 and thus their migration was likely CCR6 independent.

In regard to adaptive immunity, CCR6 is expressed by a number of adaptive immune response-related cells including T cells, B cells and DCs [3]. Our analysis indicated that CCR6 was not required during the inductive stage of the adaptive $\mathrm{T}$ cell response with regard to antigen presentation, since transgenic $\mathrm{T}$ cells proliferated effectively in the CCR6 knockout environment. In addition, CCR6 knockout mice efficiently generated cytokine-producing cells in draining lymph nodes and effectively eliminated bacteria in the adaptive response phase. These findings were fully consistent with CCR6 being a postcognate $\mathrm{T}$ effector/memory cell chemokine receptor. CCR6 has been implicated in intestinal, skin and pulmonary $\mathrm{T}$ cell-mediated immune responses [4144]. Among effector T cells, CCR6 has been strongly associated with Th17 cells, but in disease conditions it is likely expressed by subpopulations of both IL-17- and IFN- $\gamma$-producing T cells $[10,14,45]$. We identified CCR6+ $\mathrm{T}$ cells as a subpopulation of TCR- $\alpha / \beta$ T cells in the lung interstitium by flow cytometry. The emerging picture is that CCR6 is utilized by a subpopulation of effector cells that migrate from interstitium to mucosal/epithelial surfaces, with ligand contact downregulating the receptor during the process [33]. CCR6 seems to be less involved in interstitial responses such as granuloma formation, which agrees with our observation that CCR6 was redundant for elimination of $M$. bovis BCG in the adaptive phase when invasive bacteria are removed from the lung interstitium.

Since generalized airway migration of TCR- $\alpha / \beta \mathrm{T}$ cells was impaired in CCR6 knockout mice, anamnestic antimycobacterial immunity mediated by mucosal CCR6+ T effector/memory cells might be predicted to be compromised at the airway level. Developing a vaccine that confers consistent long-term antimycobacterial immunity has been difficult to achieve. In clinical trials, subcutaneous administration of $M$. bovis BCG live vaccine has been only partially effective. This reduced efficacy could be related to the generation of T memory/ effector subpopulations that lack CCR6 and are unable to prevent infection at the mucosal surface. Designing approaches that selectively enhance CCR6+ iNKT and CCR6+ T effector/memory antimycobacterial responses might overcome this obstacle.

\section{Acknowledgements}

This work was supported by the Department of Veterans Affairs and in part by NIH-NIAID grant A143460. Reagents for NKT cell detection were kindly provided by Dr. Amy Stout of the NIH Tetramer Core Facility in Atlanta, Ga., USA.

\section{References}

-1 Baba M, Imai T, Nishimura M, Kakizaki M, Takagi S, Hieshima K, Nomiyama H, Yoshie O: Identification of CCR6, the specific receptor for a novel lymphocyte-directed CC chemokine larc. J Biol Chem 1997;272:1489314898.

$>2$ Varona R, Zaballos A, Gutierrez J, Martin P, Roncal F, Albar JP, Ardavin C, Marquez G: Molecular cloning, functional characterization and mRNA expression analysis of the murine chemokine receptor CCR6 and its specific ligand mip-3 alpha. FEBS Lett 1998; 440:188-194.

$\checkmark 3$ Schutyser E, Struyf S, Van Damme J: The CC chemokine CCL20 and its receptor CCR6. Cytokine Growth Factor Rev 2003;14:409426.
4 Kucharzik T, Hudson JT, 3rd, Waikel RL, Martin WD, Williams IR: CCR6 expression distinguishes mouse myeloid and lymphoid dendritic cell subsets: demonstration using a CCR6 EGFP knock-in mouse. Eur J Immunol 2002;32:104-112.

5 Caux C, Ait-Yahia S, Chemin K, de Bouteiller O, Dieu-Nosjean MC, Homey B, Massacrier C, Vanbervliet B, Zlotnik A, Vicari A: Dendritic cell biology and regulation of dendritic cell trafficking by chemokines. Springer Semin Immunopathol 2000;22:345-369.

6 Homey B, Dieu-Nosjean MC, Wiesenborn A, Massacrier C, Pin JJ, Oldham E, Catron D, Buchanan ME, Muller A, deWaal Malefyt R, Deng G, Orozco R, Ruzicka T, Lehmann P, Lebecque S, Caux C, Zlotnik A: Up-regula- tion of macrophage inflammatory protein-3 $\alpha /$ CCL20 and CC chemokine receptor 6 in psoriasis. J Immunol 2000;164:6621-6632.

$>7$ Kobayashi H, Miura S, Nagata H, Tsuzuki Y, Hokari R, Ogino T, Watanabe C, Azuma T, Ishii $\mathrm{H}$ : In situ demonstration of dendritic cell migration from rat intestine to mesenteric lymph nodes: relationships to maturation and role of chemokines. J Leukoc Biol 2004;75:434-442.

8 Le Borgne M, Etchart N, Goubier A, Lira SA, Sirard JC, van Rooijen N, Caux C, Ait-Yahia S, Vicari A, Kaiserlian D, Dubois B: Dendritic cells rapidly recruited into epithelial tissues via CCR6/CCL20 are responsible for CD8+ T cell crosspriming in vivo. Immunity 2006;24:191-201. 
-9 Salazar-Gonzalez RM, Niess JH, Zammit DJ, Ravindran R, Srinivasan A, Maxwell JR, Stoklasek T, Yadav R, Williams IR, Gu X, McCormick BA, Pazos MA, Vella AT, Lefrancois L, Reinecker HC, McSorley SJ: CCR6-mediated dendritic cell activation of pathogen-specific T cells in Peyer's patches. Immunity 2006;24:623-632.

10 Kim CH: Migration and function of Th17 cells. Inflamm Allergy Drug Targets 2009;8: 221-228.

- 11 Villares R, Cadenas V, Lozano M, Almonacid L, Zaballos A, Martinez AC, Varona R: CCR6 regulates EAE pathogenesis by controlling regulatory $\mathrm{CD} 4+\mathrm{T}$-cell recruitment to target tissues. Eur J Immunol 2009;39: 1671-1681.

12 Reibman J, Hsu Y, Chen LC, Bleck B, Gordon T: Airway epithelial cells release mip-3 $3 /$ CCL20 in response to cytokines and ambient particulate matter. Am J Respir Cell Mol Biol 2003;28:648-654.

-13 Starner TD, Barker CK, Jia HP, Kang Y, McCray PB Jr: Ccl20 is an inducible product of human airway epithelia with innate immune properties. Am J Respir Cell Mol Biol 2003; 29:627-633.

14 Facco M, Baesso I, Miorin M, Bortoli M, Cabrelle A, Boscaro E, Gurrieri C, Trentin L, Zambello R, Calabrese F, Cassatella MA, Semenzato G, Agostini C: Expression and role of CCR6/CCL20 chemokine axis in pulmonary sarcoidosis. J Leukoc Biol 2007;82:946955.

-15 Francis JN, Sabroe I, Lloyd CM, Durham SR, Till SJ: Elevated CCR6+ CD4+ t lymphocytes in tissue compared with blood and induction of CCL20 during the asthmatic late response. Clin Exp Immunol 2008;152:440-447.

$\checkmark 16$ Korbel DS, Schneider BE, Schaible UE: Innate immunity in tuberculosis: myths and truth. Microbes Infect 2008;10:995-1004.

$\checkmark 17$ Junqueira-Kipnis AP, Kipnis A, Jamieson A, Juarrero MG, Diefenbach A, Raulet DH, Turner J, Orme IM: NK cells respond to pulmonary infection with mycobacterium tuberculosis, but play a minimal role in protection. J Immunol 2003;171:6039-6045.

18 Kawamura I: Protective immunity against mycobacterium tuberculosis. Kekkaku 2006;81:687-691.

-19 Emoto M, Emoto Y, Buchwalow IB, Kaufmann SH: Induction of IFN- $\gamma$-producing CD4+ natural killer T cells by Mycobacterium bovis bacillus Calmette Guerin. Eur J Immunol 1999;29:650-659.

20 Dieli F, Ivanyi J, Marsh P, Williams A, Naylor I, Sireci G, Caccamo N, Di Sano C, Salerno A: Characterization of lung $\gamma \delta$ T cells following intranasal infection with mycobacterium bovis bacillus calmette-guerin. J Immunol 2003;170:463-469.

-21 Venkataswamy MM, Porcelli SA: Lipid and glycolipid antigens of CD1d-restricted natural killer T cells. Semin Immunol 2009;22: 68-78.
2 Cook DN, Prosser DM, Forster R, Zhang J, Kuklin NA, Abbondanzo SJ, Niu XD, Chen SC, Manfra DJ, Wiekowski MT, Sullivan LM, Smith SR, Greenberg HB, Narula SK, Lipp M, Lira SA: CCR6 mediates dendritic cell localization, lymphocyte homeostasis, and immune responses in mucosal tissue. Immunity 2000;12:495-503.

23 Chiu BC, Shang XZ, Stolberg VR, Komuniecki E, Chensue SW: Population analysis of $\mathrm{CD} 4+\mathrm{T}$ cell chemokine receptor transcript expression during in vivo type-1 (mycobacterial) and type-2 (schistosomal) immune responses. J Leukoc Biol 2002;72:363-372.

24 Chiu BC, Stolberg VR, Chensue SW: Mononuclear phagocyte-derived IL-10 suppresses the innate IL-12/IFN- $\gamma$ axis in lung-challenged aged mice. J Immunol 2008; 181:31563166.

25 Chiu BC, Freeman CM, Stolberg VR, Hu JS, Zeibecoglou K, Lu B, Gerard C, Charo IF, Lira SA, Chensue SW: Impaired lung dendritic cell activation in CCR2 knockout mice. Am J Pathol 2004;165:1199-1209.

26 Qiu B, Frait KA, Reich F, Komuniecki E, Chensue SW: Chemokine expression dynamics in mycobacterial (type-1) and schistosomal (type-2) antigen-elicited pulmonary granuloma formation. Am J Pathol 2001;158: 1503-1515.

27 Chiu BC, Freeman CM, Stolberg VR, Komuniecki E, Lincoln PM, Kunkel SL, Chensue SW: Cytokine-chemokine networks in experimental mycobacterial and schistosomal lung granuloma formation. Am J Respir Cell Mol Biol 2003;10:106-116.

28 Wolf AJ, Desvignes L, Linas B, Banaiee N, Tamura T, Takatsu K, Ernst JD: Initiation of the adaptive immune response to mycobacterium tuberculosis depends on antigen production in the local lymph node, not the lungs. J Exp Med 2008;205:105-115.

29 Im JS, Kang TJ, Lee SB, Kim CH, Lee SH, Venkataswamy MM, Serfass ER, Chen B, Illarionov PA, Besra GS, Jacobs WR Jr, Chae GT, Porcelli SA: Alteration of the relative levels of iNKT cell subsets is associated with chronic mycobacterial infections. Clin Immunol 2008;127:214-224.

- 30 Sada-Ovalle I, Chiba A, Gonzales A, Brenner MB, Behar SM: Innate invariant NKT cells recognize mycobacterium tuberculosis-infected macrophages, produce interferon- $\gamma$, and kill intracellular bacteria. PLoS Pathog 2008;4:e1000239.

- 31 Thomas SY, Hou R, Boyson JE, Means TK, Hess C, Olson DP, Strominger JL, Brenner MB, Gumperz JE, Wilson SB, Luster AD: CD1d-restricted NKT cells express a chemokine receptor profile indicative of Th1-type inflammatory homing cells. J Immunol 2003;171:2571-2580.
32 Doisne JM, Becourt C, Amniai L, Duarte N, Le Luduec JB, Eberl G, Benlagha K: Skin and peripheral lymph node invariant NKT cells are mainly retinoic acid receptor-related orphan receptor $(\gamma) t+$ and respond preferentially under inflammatory conditions. J Immunol 2009;183:2142-2149.

-33 Thomas SY, Banerji A, Medoff BD, Lilly CM, Luster AD: Multiple chemokine receptors, including CCR6 and CXCR3, regulate antigen-induced $\mathrm{T}$ cell homing to the human asthmatic airway. J Immunol 2007;179:19011912.

34 Sugawara I: Why does tuberculosis lead to specific inflammation? Nihon Hansenbyo Gakkai Zasshi 2009;78:263-269.

35 Lee JS, Lee JY, Son JW, Oh JH, Shin DM, Yuk JM, Song CH, Paik TH, Jo EK: Expression and regulation of the CC-chemokine ligand 20 during human tuberculosis. Scand J Immunol 2008;67:77-85.

36 Chackerian A, Alt J, Perera V, Behar SM: Activation of NKT cells protects mice from tuberculosis. Infect Immun 2002;70:63026309.

37 Behar SM, Porcelli SA: Cd1-restricted T cells in host defense to infectious diseases. Curr Top Microbiol Immunol 2007;314:215-250.

- 38 Snyder-Cappione JE, Nixon DF, Loo CP, Chapman JM, Meiklejohn DA, Melo FF, Costa PR, Sandberg JK, Rodrigues DS, Kallas EG: Individuals with pulmonary tuberculosis have lower levels of circulating CD1drestricted NKT cells. J Infect Dis 2007;195: 1361-1364.

-39 Inoue T, Yoshikai Y, Matsuzaki G, Nomoto $\mathrm{K}$ : Early appearing $\gamma / \delta$-bearing T cells during infection with Calmette Guerin bacillus. J Immunol 1991;146:2754-2762.

- 40 Ladel CH, Blum C, Dreher A, Reifenberg K, Kaufmann SH: Protective role of $\gamma / \delta$ T cells and $\alpha / \beta$ T cells in tuberculosis. Eur J Immunol 1995;25:2877-2881.

41 Paradis TJ, Cole SH, Nelson RT, Gladue RP: Essential role of CCR6 in directing activated $\mathrm{T}$ cells to the skin during contact hypersensitivity. J Invest Dermatol 2008;128:628-633.

42 Williams IR: CCR6 and CCL20: partners in intestinal immunity and lymphorganogenesis. Ann NY Acad Sci 2006;1072:52-61.

43 Harrison OJ, Foley J, Bolognese BJ, Long E, 3rd, Podolin PL, Walsh PT: Airway infiltration of CD4+ CCR6+ Th17 type cells associated with chronic cigarette smoke induced airspace enlargement. Immunol Lett 2008; 121:13-21.

44 Lundy SK, Lira SA, Smit JJ, Cook DN, Berlin AA, Lukacs NW: Attenuation of allergen-induced responses in CCR6-/- mice is dependent upon altered pulmonary $t$ lymphocyte activation. J Immunol 2005; 174:2054-2060.

45 Brand S: Crohn's disease: Th1, Th17 or both? The change of a paradigm: new immunological and genetic insights implicate Th17 cells in the pathogenesis of Crohn's disease. Gut 2009;58:1152-1167. 